\title{
Global and local processing by 3- and 4-month-old infants
}

\author{
HEI-RHEE GHIM and PETER D. EIMAS \\ Brown University, Providence, Rhode Island
}

\begin{abstract}
In two experiments with 3- and 4-month-old infants, we used a familiarization/novelty preference procedure to assess the ability of infants to acquire information about the global and local information in a complex visual pattern. The initial experiment established that individual infants were able to acquire and remember information about both the global forms and the local forms from which the global patterns were constructed. In addition, we found that the global and local forms were of nearly equal discriminability. Using these patterns and a Stroop-like interference paradigm, in the second experiment we obtained evidence for a global precedence effect that could not, we argue, be attributed solely to a difference in discriminability favoring the global stimuli.
\end{abstract}

In recent years, the perception of visual patterns has been shown to involve the processing of holistic properties as well as more elementary featural properties. Moreover, the presence of holistic information has often influenced the perception of the components. For example, Weisstein and Harris (1974) demonstrated that the identification of simple line targets was better when the targets were embedded in a coherent contextual frame that was perceived as three-dimensional than when they were embedded in less coherent arrays that appeared twodimensional. Even more compelling evidence for an effect of holistic information on the perception of component parts was provided by Williams and Weisstein (1978). They showed a facilitating effect of a contextual frame on the identification of line targets even when the comparison condition involved presenting the line targets in isolation. This pattern-line effect has also been obtained with measures of discriminability (e.g., Pomerantz, Sager, \& Stoever, 1977), and, interestingly, it has been replicated with infants as young as 3 months of age (Bomba, Eimas, Siqueland, \& Miller, 1984; Colombo, Laurie, Martelli, \& Hartig, 1984; Quinn \& Eimas, 1986). The existence of pattern-line effects is taken as strong evidence that the perception of visual patterns does not proceed solely by first processing simple featural information, but rather involves the use of more complex configural information during the early stages of perception (e.g., Enns \& Printzmetal, 1984; McClelland \& Miller, 1979; Navon, 1977). Moreover, Navon $(1977,1981,1983)$ has argued strongly for what he has called a global precedence effect-the hypothesis that "perceptual processing pro-

This research was supported by Grant HD 05331-17 from the National Institute of Child Health and Human Development. We thank Joanne L. Miller, Gregory L. Murphy, and Bryan E. Shepp for their critical comments on earlier versions of this article and we thank June Shepp and Bonnie Tracy for assistance in testing subjects. Correspondence and requests for reprints should be sent to Peter D. Eimas at the Department of Psychology, Brown University, Providence, RI 02912. ceeds from the global structure to the more local details" (Navon, 1983, p. 239). This strong view of processing has generated both controversy and considerable research.

A common method of testing for a global (or local) precedence presents observers with large letters made up of small letters. The global and local letters may either match or not-that is, they may be consistent or inconsistent-and the observer's task is to identify the global letters on some trials and the local letters on other trials. The patterns are presented briefly and the observers are urged to respond rapidly. What has been found often by Navon (1977) and others is that response times to the global letters are unaffected by conflicting local characters, whereas the response times to the local letters are reliably slowed by the presence of inconsistent global letters-a Stroop-like form of interference (see Pomerantz, 1983). However, a global precedence is not always evidenced. For example, Martin (1979) found a local precedence when the global letters were constructed from only a few local letters and Hoffman (1980) found either a global or local precedence by reducing the quality (goodness) of the local or global letters, respectively. Not surprisingly, the size of the forms appears to determine which precedence effect will be obtained (Kinchla \& Wolfe, 1979), as does the relative discriminability of the global and local information (Pomerantz, 1983). As Pomerantz noted, there is reasonable evidence for both local and global precedence effects, but there is very little in the way of theory to explain how or when these effects will appear or what level or levels of processing they involve (see Miller, 1981). Moreover, in light of these results, we would argue that Pomerantz's (1983) definition of precedence effects in terms of one level's dominating the other and thereby capturing attention is more fitting than definitions that involve assumptions about an obligatory order of processing.

Although there have been direct tests of pattern-line effects in infants and even an attempt to determine the manner in which contextual frames alter the discrimina- 
bility of line targets in these subjects (Quinn \& Eimas, 1986), there has been only one study to our knowledge that is directly related to the study of precedence effects in infants, that by Vurpillot, Ruel, and Castrec (1977). ${ }^{1}$ They found that 2- and 4-month-old infants perceived the differences in global forms that were made of local elements. The local elements, which were small, were not discriminated. When the local elements were larger, however, the infants perceived a change in the local elements but not a change in the global pattern. It is apparent that inferences about the existence of precedence effects must be drawn with caution from this study, inasmuch as Vurpillot et al. never demonstrated that their infants could in fact process both global and local information in a single experimental setting. Furthermore, as Van Giffen and Haith (1984) noted, the perception of a change in the global pattern may actually have been based on a change in area of the global patterns or positioning of the local elements. Be that as it may, Vurpillot et al.'s study makes it quite clear that it is necessary to determine that infants are able to process the information at both the global and local levels and that both sources of information are approximately equally discriminable before statements about precedence effects are possible. It is also necessary, as Navon (1977) and Miller (1981) noted, to construct the patterns with identical global and local forms. This avoids confounding factors that might arise from differences in the importance or salience of the global and local properties or from differences in experience with them. In the present experiments we tested for global and local processing with global and local forms that were identical except for the necessary difference in size. It should be noted that although there is considerable evidence favoring the idea that infants by the age of 3 months are able to process form per se (e.g., Caron, Caron, \& Carlson, 1978, 1979; Milewski, 1979), it is not a requirement of our experiments that this ability actually exist. All that is necessary is that the information at both levels be the same; whether the infants process the holistic figural or simple featural aspects of the global and local forms is immaterial to the purposes of the present experiments.

\section{EXPERIMENT 1}

Experiment 1 was designed to determine whether infants were able to process information at both the global and local levels, and if this were possible, to determine whether the global and local forms were at least approximately equally discriminable-the two preconditions that must be met before tests of precedence effects are possible. Infants were presented with global squares and diamonds made of local squares and diamonds or with global crosses and Xs made of local crosses and Xs. Each infant was first familiarized with a single pattern that was one of the eight possible stimulus patterns, for example, a global square made of local squares. Immediately after the familiarization period, a preference test was ad- ministered in which the familiar stimulus was paired with a novel stimulus that differed from the former with respect to the global or local form. For the present example, the novel stimulus for a global preference test would be a global diamond made of local squares, and for a local preference test it would be a global square made of local diamonds. Assuming that infants prefer the novel stimulus, as they tend to do by 2 months of age (Cohen \& Gelber, 1975), we might infer that information about the familiar global or local pattern was remembered and differentiated from information about the novel pattern. The difference between the magnitudes of the global and local tests of novelty preference provides an estimate of their relative discriminability. Finally, if more infants showed a novelty preference for both the global and local forms than would be expected by chance, we might conclude that individual infants acquired information about both the local and global forms during the familiarization period. ${ }^{2}$

\section{Method}

Subjects. Nineteen 3-month-old and 13 4-month-old infants (16 females and 16 males) served as subjects. Fifteen additional infants were tested: 12 failed to complete the experiment because of excessive fussiness or crying and 3 were excluded from the data analyses because of fussiness, position preference, or experimenter error ( 1 infant in each case). All of the infants were from the greater Providence, Rhode Island, area and were recruited by contacting their mothers shortly after the birth of their children, when they were still patients at the Women and Infants Hospital of Rhode Island.

Apparatus and Stimuli. A portable visual-preference apparatus, adapted from the one described by Fagan (1970), was used. The critical feature of the apparatus is a hinged gray panel that contains two compartments into which $17.7 \times 17.7 \mathrm{~cm}$ stimulus cards can be inserted. The center-to-center distance between compartments is $30.5 \mathrm{~cm}$. There is also a peephole, $0.625 \mathrm{~cm}$ in diameter, positioned midway between the two stimulus compartments through which an experimenter can see the infant's fixations to the stimuli. During a trial, when the panel is closed, the distance between the center of the panel and the infant's eyes is approximately $30 \mathrm{~cm}$.

There were two sets of stimuli, one composed of local and global squares and diamonds and one composed of local and global crosses and Xs. The squares and diamonds had the following dimensions: The length of each side of the local square was $2 \mathrm{~cm}\left(3.8^{\circ}\right)$, and each side of the diamond was $2.2 \mathrm{~cm}\left(4.2^{\circ}\right)$. The width of the local diamond was $2.7 \mathrm{~cm}\left(5.1^{\circ}\right)$ and the height was $3.5 \mathrm{~cm}\left(6.7^{\circ}\right)$. The area of the local square was $4 \mathrm{~cm}^{2}$, and that of the local diamond was $4.7 \mathrm{~cm}^{2}$. The sides of the global square and the global diamond were $10.7 \mathrm{~cm}\left(19.6^{\circ}\right)$ and $10.9 \mathrm{~cm}\left(20^{\circ}\right)$, respectively. The width of the global diamond was $13.4 \mathrm{~cm}\left(24.1^{\circ}\right)$ and its height was $17.5 \mathrm{~cm}\left(30.2^{\circ}\right)$. The area of the global square was $114.5 \mathrm{~cm}^{2}$, and that of the global diamond was $117.3 \mathrm{~cm}^{2}$.

The crosses and Xs had the following dimensions: The local cross was $2.5 \mathrm{~cm}\left(4.8^{\circ}\right)$ in height and width. The height of the local X was $2.5 \mathrm{~cm}\left(4.8^{\circ}\right)$ and its width was $2.0 \mathrm{~cm}\left(3.8^{\circ}\right)$. The areas of the local cross and the local X were 3.2 and $3.1 \mathrm{~cm}^{2}$, respectively. The global cross was $15.5 \mathrm{~cm}\left(27.3^{\circ}\right)$ in height and width; the global $\mathrm{X}$ was $15.5 \mathrm{~cm}\left(27.3^{\circ}\right)$ in height and $12.6 \mathrm{~cm}\left(22.8^{\circ}\right)$ in width. The areas of the global cross and the global $X$ were 72.2 and $90.0 \mathrm{~cm}^{2}$, respectively.

As is evident, the diamonds and $\mathrm{Xs}$ were not simply $45^{\circ}$ rotations of the squares and crosses. The reason for this is that we wished 
to enhance the difference between the stimuli in each set and to prevent the possibility that the infants would be able to discriminate between the forms in each set solely on the basis of orientation.

Procedure. The infants were tested individually. Each infant was placed in a reclining position on the mother's lap, with his/her head against the mother's abdomen. An experimenter then wheeled the apparatus over the infant, keeping the infant's head centered with respect to the midline of the display panel. With the apparatus in this position, the mother could not see the stimulus patterns. As soon as the infant was properly aligned and apparently at ease, the familiarization phase was begun. An experimenter fitted two identical stimulus cards into the two compartments, drew the attention of the infant to the experimenter (who could be seen when the panel was down), and then folded up the display panel. There were six 15 -sec familiarization trials, with approximately $10 \mathrm{sec}$ between trials, although the intertrial period was longer if the baby was fussy or inattentive. During the $15 \mathrm{sec}$ when the display panel was folded up, an experimenter observed the infant through the peephole and recorded the duration of the infant's fixations to each stimulus, separately, with two Cronus 4 electronic stopwatches, one held in each hand. The criterion for a fixation was the experimenter's observation of a single stimulus reflected from the infant's cornea and centered on the pupil. Interobserver reliability of this measure is high, ranging from 0.88 to 0.93 (Bomba, 1984). Immediately after the familiarization period, two 10 -sec test trials were administered in which the familiar stimulus was presented together with the appropriate novel stimulus. In order to prevent experimenter bias, a different experimenter recorded the infant's fixations on the test trials. The second experimenter was not aware of the stimulus that had been used during the familiarization phase.

Half of the infants were randomly assigned to each of the two stimulus sets, and within each stimulus set, half of the infants were randomly assigned to either the global or the local preference test. Within each of these four subgroups, 2 infants were familiarized with each of the four possible stimuli. In the set of stimuli made from squares and diamonds, the four familiarization stimuli were global diamonds made of local squares or local diamonds and global squares made of local squares or local diamonds. In the set of Xs and crosses, the four familiarization stimuli were global Xs made of local Xs or local crosses and global crosses made of local crosses or local Xs. Table 1 shows examples of the arrangements of stimuli, in this case squares and diamonds, that were used for global and local tests of preference after familiarization with patterns that had either consistent or inconsistent global and local forms. During the two test trials, the left-right positioning of the novel and familiar stimuli were appropriately counterbalanced across infants on the first test trial and then reversed on the second test trial.

\section{Results and Discussion}

Familiarization phase. Table 2 shows the mean looking times and corresponding standard deviations for blocks of three trials and for all six trials. The infant's fixation times to each of the two identical familiarization patterns have been summed. An analysis of variance, trials (1-3 vs. 4-6) $\times$ type of preference test (global vs. local) $\times$ consistency of familiarization forms (consistent vs. inconsistent) $\times$ familiar test form (square vs. diamond vs. cross vs. $\mathrm{X}$ ), was performed on the individual fixation times. The variable of familiar test form refers to the global or local component of the familiarization stimulus that was experienced during the familiarization period and later paired with a novel global or local form for the preference test. There was a highly significant effect of trials $[F(1,16)=19.81, p<.001]$; the infants showed a
Table 1

Examples of Stimulus Arrangements Used During Familiarization and Test Phases in Experiment 1

\begin{tabular}{|c|c|c|c|}
\hline \multicolumn{2}{|c|}{ Familiarization } & \multicolumn{2}{|c|}{ Test Stimuli } \\
\hline Forms & Stimulus & Familiar & Novel \\
\hline \multicolumn{4}{|c|}{ Global Preference Test } \\
\hline Consistent & $\begin{array}{c}\text { Global square } \\
\text { made of } \\
\text { local squares }\end{array}$ & $\begin{array}{l}\text { Global square } \\
\text { made of } \\
\text { local squares }\end{array}$ & $\begin{array}{l}\text { Global diamond } \\
\text { made of } \\
\text { local squares }\end{array}$ \\
\hline Inconsistent & $\begin{array}{l}\text { Global square } \\
\text { made of } \\
\text { local diamonds }\end{array}$ & $\begin{array}{l}\text { Global square } \\
\text { made of } \\
\text { local diamonds }\end{array}$ & $\begin{array}{l}\text { Global diamond } \\
\text { made of } \\
\text { local diamonds }\end{array}$ \\
\hline \multicolumn{4}{|c|}{ Local Preference Test } \\
\hline Consistent & $\begin{array}{l}\text { Global square } \\
\text { made of } \\
\text { local squares }\end{array}$ & $\begin{array}{l}\text { Global square } \\
\text { made of } \\
\text { local squares }\end{array}$ & $\begin{array}{l}\text { Global square } \\
\text { made of } \\
\text { local diamonds }\end{array}$ \\
\hline Inconsistent & $\begin{array}{l}\text { Global square } \\
\text { made of } \\
\text { local diamonds }\end{array}$ & $\begin{array}{l}\text { Global square } \\
\text { made of } \\
\text { local diamonds }\end{array}$ & $\begin{array}{l}\text { Global square } \\
\text { made of } \\
\text { local squares }\end{array}$ \\
\hline
\end{tabular}

decrease in looking time across trials, presumably as a consequence of becoming familiar with the patterns. There were no other main effects or interactions that reached statistical significance at the .05 level.

Preference test phase. A novelty preference score (percentage) was computed for each infant by dividing the time the novel stimulus was observed during the two test trials by the total time over the two test trials that the novel and familiar stimuli were fixated and then multiplying the score by 100 . The mean preference scores, together with their standard deviations and $t$ values (vs. chance), are shown in Table 3. All four of the mean scores are greater than the chance level of $50 \%$ ( $p<.025$ in each case) ${ }^{3}$ Moreover, 29 of the 32 infants had preference scores greater than $50 \%(p<.001)$, and at least 7 of 8 infants had above-chance scores in each treatment condition $(p<.03)$. The individual preference scores were also evaluated by an analysis of variance (type of preference test $\times$ consistency of familiarization forms $\times$ familiar test form). There were no reliable main effects or interactions ( $p>.10$ for each $F$ value).

In sum, the evidence from Experiment 1 strongly supports the contention that infants are able to process and remember both local and global information during familiarization. There was no evidence, moreover, of a difference in discriminability between the local and global

Table 2

Mean Looking Times (in sec) and SDs During the Familiarization Phase of Experiment 1

\begin{tabular}{|c|c|c|c|c|c|c|}
\hline \multirow{3}{*}{$\begin{array}{l}\text { Familiarization } \\
\text { Forms }\end{array}$} & \multicolumn{6}{|c|}{ Trials } \\
\hline & \multicolumn{2}{|c|}{$1-3$} & \multicolumn{2}{|c|}{$4-6$} & \multicolumn{2}{|c|}{ All } \\
\hline & $M$ & $S D$ & $M$ & $S D$ & $M$ & $S D$ \\
\hline \multicolumn{7}{|c|}{ Global Preference Test } \\
\hline Consistent & 4.16 & 1.68 & 3.27 & 1.55 & 3.72 & 1.63 \\
\hline Inconsistent & 5.59 & 1.60 & 3.93 & 1.62 & 4.76 & 1.78 \\
\hline \multicolumn{7}{|c|}{ Local Preference Test } \\
\hline Consistent & 4.70 & 1.74 & 3.27 & 1.86 & 3.99 & 1.89 \\
\hline Inconsistent & 4.66 & 1.83 & 3.93 & 1.78 & 4.30 & 1.78 \\
\hline
\end{tabular}


Table 3

Mean Novelty Preference Scores (in \%), $S D \mathrm{~s}$, and $t$ Values (vs. Chance) in Experiment 1

\begin{tabular}{cccc}
\hline $\begin{array}{c}\text { Familiarization } \\
\text { Forms }\end{array}$ & $M$ & $S D$ & $t$ \\
\hline & Global Preference & Test \\
Consistent & 63.28 & 6.58 & $5.70 \dagger$ \\
Inconsistent & 60.76 & 11.92 & $2.56^{*}$ \\
& \multicolumn{4}{c}{} \\
Local Preference & Test \\
Consistent & 64.66 & 16.87 & $2.46^{*}$ \\
Inconsistent & 63.93 & 13.25 & $2.98^{*}$ \\
\hline
\end{tabular}

${ }^{*} p<.025 . \quad \dagger p<.01$

forms. Thus, in Experiment 1 we satisfied the major requirements for assessing the existence of precedence effects in infants, namely, that information at both levels is acquired by individual infants and that global and local forms are approximately equally discriminable.

\section{EXPERIMENT 2}

To obtain evidence for precedence effects, we used a procedure that could be expected to induce Stroop-like interference during the novelty preference test. This was accomplished by administering a second set of test trials with stimulus patterns that had an additional, competing source of novelty. The following illustrates the procedure (see the examples in Table 4 with consistent forms during familiarization). If an infant was familiarized with a global square made of local squares, then the test patterns for a test of global novelty were the familiar global square and a novel global diamond, both of which were constructed from novel local diamonds. The novel local diamonds in each pattern provided the second, competing source of novelty. For a test of local novelty, the two test patterns were both novel global diamonds, with one global form made of familiar local squares and the other made of novel local diamonds. The global diamonds were then

Table 4

Examples of Stimulus Arrangements Used During Familiarization and Test Phases in Experiment 2 When There Was a Competing Source of Novelty

\begin{tabular}{|c|c|c|c|}
\hline \multicolumn{2}{|c|}{ Familiarization } & \multicolumn{2}{|c|}{ Test Stimuli } \\
\hline Forms & Stimulus & Familiar & Novel \\
\hline \multicolumn{4}{|c|}{ Global Preference Test } \\
\hline Consistent & $\begin{array}{l}\text { Global square } \\
\text { made of } \\
\text { local squares }\end{array}$ & $\begin{array}{l}\text { Global square } \\
\text { made of } \\
\text { local diamonds }\end{array}$ & $\begin{array}{l}\text { Global diamond } \\
\text { made of } \\
\text { local diamonds }\end{array}$ \\
\hline Inconsistent & $\begin{array}{l}\text { Global square } \\
\text { made of } \\
\text { local diamonds }\end{array}$ & $\begin{array}{l}\text { Global square } \\
\text { made of } \\
\text { local squares }\end{array}$ & $\begin{array}{l}\text { Global diamond } \\
\text { made of } \\
\text { local squares }\end{array}$ \\
\hline \multicolumn{4}{|c|}{ Local Preference Test } \\
\hline Consistent & $\begin{array}{l}\text { Global square } \\
\text { made of } \\
\text { local squares }\end{array}$ & $\begin{array}{l}\text { Global diamond } \\
\text { made of } \\
\text { local squares }\end{array}$ & $\begin{array}{l}\text { Global diamond } \\
\text { made of } \\
\text { local diamonds }\end{array}$ \\
\hline Inconsistent & $\begin{array}{l}\text { Global square } \\
\text { made of } \\
\text { local diamonds }\end{array}$ & $\begin{array}{l}\text { Global diamond } \\
\text { made of } \\
\text { local diamonds }\end{array}$ & $\begin{array}{l}\text { Global diamond } \\
\text { made of } \\
\text { local squares }\end{array}$ \\
\hline
\end{tabular}

the competing source of novelty. We reasoned that if the infants noticed and attended to this second source of novelty, then the usual preference for novel test forms would be in competition with a tendency to look at this other source of novelty, which was present in both test patterns. That is to say, if this additional form of novelty attracted the infants to any extent, it should tend to lower the preference scores, inasmuch as both test patterns now contained novel elements. Moreover, should greater interference in the preference test arise from the additional novelty provided by either the global or local forms, this would provide evidence for a precedence effect, as defined by Pomerantz (1983).

\section{Method}

Subjects. Forty-four 3-month-old and 20 4-month-old infants (27 females and 37 males) served as subjects. Twenty-nine additional infants were tested: 16 did not complete the experiment because of fussiness or crying and 13 were excluded from the analysis because of fussiness $(n=6)$, position preference $(n=6)$, or experimenter error $(n=1)$. The infants were from the same population and were recruited in the same manner as described in Experiment 1 .

Apparatus and Stimuli. The apparatus and stimuli were the same as those used in Experiment 1.

Procedure. As in Experiment 1, each infant was randomly assigned to one of the two stimulus sets, and within each stimulus set, the infants were randomly assigned to either the local or the global preference test and to one of the four possible familiarization stimuli. There were thus 4 infants in each of these treatment combinations. The familiarization phase was identical to that used in Experiment 1. The test period differed, however, in that it now consisted of four 10 -sec trials. Two of the test trials were the same as those previously administered, having patterns without a second source of novelty (see Table 1). For the remaining two test trials, the two patterns had a second, competing source of novelty that was identical in both patterns. Several examples of this type of stimulus arrangement are given in Table 4 . Consider only the cases in which the global and local forms were inconsistent during familiarization, as we have already described examples in which the familiar forms were consistent. If the familiarization pattern was a global square made of local diamonds, the test patterns for a global preference test consisted of a familiar global square and a novel global diamond, both of which were made of novel local squares. The novel local squares were the competing source of novelty. When a local preference test was administered, the two patterns consisted of familiar local diamonds and novel local squares arranged to form novel global diamonds in each pattern. The novel global diamonds were then the competing source of novelty. The order in which each set of test trials was administered was counterbalanced across infants, as was the positioning of the patterns within each set of test trials.

\section{Results and Discussion}

Familiarization phase. Table 5 presents the mean looking times and corresponding standard deviations averaged over blocks of three trials and over all trials. An analysis of variance, trials $\times$ type of preference test $\times$ consistency of familiarization forms $\times$ familiar test form, was performed on the individual looking times. There was again a highly significant effect of trials $[F(1,48)=60.28$, $p<.001]$; the decrement in looking times over trials again suggests that the infants were habituating to patterns 
Table 5

Mean Looking Times (in sec) and $S D$ s During the Familiarization Phase of Experiment 2

\begin{tabular}{|c|c|c|c|c|c|c|}
\hline \multirow{3}{*}{$\begin{array}{c}\text { Familiarization } \\
\text { Forms }\end{array}$} & \multicolumn{6}{|c|}{ Test Trials } \\
\hline & \multicolumn{2}{|c|}{$1-3$} & \multicolumn{2}{|c|}{ 4-6 } & \multicolumn{2}{|c|}{ All } \\
\hline & $M$ & $S D$ & $M$ & $S D$ & $\bar{M}$ & $\overline{S D}$ \\
\hline \multicolumn{7}{|c|}{ Global Preference Test } \\
\hline Consistent & 4.82 & 1.49 & 3.62 & 1.45 & 4.22 & 1.57 \\
\hline Inconsistent & 4.93 & 1.47 & 3.88 & 1.66 & 4.40 & 1.63 \\
\hline \multicolumn{7}{|c|}{ Local Preference Test } \\
\hline Consistent & 4.62 & 1.10 & 3.57 & 1.57 & 4.10 & 1.44 \\
\hline Inconsistent & 5.24 & 1.15 & 4.03 & 0.98 & 4.64 & 1.21 \\
\hline
\end{tabular}

with repeated exposures. There was also a significant trials $\times$ familiar test form interaction $[F(3,48)=2.94$, $p<.05]$; the decrease across trials was greater for patterns with crosses and Xs than for patterns with squares and diamonds. We have no explanation of this effect or why it occurred only in Experiment 2. Most important for our purposes, it was not related to the subsequent testtrial scores.

Preference test phase. The mean novelty preference scores are shown in Table 6, together with their standard deviations and $t$ values (vs. chance). The scores were computed as in Experiment 1. Consider first the four conditions that constituted a near replication of Experiment 1, in that the infants received test-trial patterns that had no competing source of novelty (see Table 1). The only difference between the two experiments for these conditions is that in Experiment 2 half of the preference test scores were obtained on the first set of test trials and half on the second set of trials, whereas in Experiment 1 there was only a single set of test trials. Comparisons across experiments reveal a markedly close pattern of results. In all four conditions in each experiment, infants had preference scores greater than chance $(p<.025$ in each instance), and the overall means differed by less than $2 \%$ across experiments. In addition, an analysis of variance of the data from Experiment 2, type of preference test $\times$ consistency of familiarization forms $\times$ familiar test form $\times$ test trial set (1st vs. 2nd), revealed, as in Experiment 1 , no reliable main effects or interactions $(p>.10$ for each $F$ value). Finally, 55 of 64 infants in Experiment 2 had preference scores greater than chance $(p<.001)$, which compares closely with the 29 of 32

Table 6

Mean Novelty Preference Scores (in \%), SDs, and $t$ Values (vs. Chance) in Experiment 2

\begin{tabular}{|c|c|c|c|c|c|c|}
\hline \multirow{3}{*}{$\begin{array}{c}\text { Familiarization } \\
\text { Forms }\end{array}$} & \multicolumn{6}{|c|}{ Competing Source of Novelty } \\
\hline & \multicolumn{3}{|c|}{ Absent } & \multicolumn{3}{|c|}{ Present } \\
\hline & $M$ & $S D$ & $t$ & $M$ & $S D$ & $t$ \\
\hline \multicolumn{7}{|c|}{ Global Preference Test } \\
\hline $\begin{array}{l}\text { Consistent } \\
\text { Inconsistent }\end{array}$ & $\begin{array}{l}60.12 \\
62.39\end{array}$ & $\begin{array}{r}9.41 \\
11.80\end{array}$ & $\begin{array}{l}4.31^{*} \\
4.20^{*}\end{array}$ & $\begin{array}{l}65.98 \\
50.56\end{array}$ & $\begin{array}{l}12.61 \\
13.09\end{array}$ & $\begin{array}{l}5.07^{*} \\
0.17\end{array}$ \\
\hline \multicolumn{7}{|c|}{ Local Preference Test } \\
\hline $\begin{array}{l}\text { Consistent } \\
\text { Inconsistent }\end{array}$ & $\begin{array}{l}63.47 \\
58.95\end{array}$ & $\begin{array}{l}15.51 \\
11.13\end{array}$ & $\begin{array}{l}3.47^{*} \\
3.13^{*}\end{array}$ & $\begin{array}{l}52.21 \\
46.54\end{array}$ & $\begin{array}{r}13.29 \\
8.30\end{array}$ & $\begin{array}{r}0.67 \\
-1.66\end{array}$ \\
\hline
\end{tabular}

infants who performed above chance in Experiment 1. In each condition, averaged over stimulus sets, at least 13 of 16 infants had scores above chance $(p<.025)$. Thus, the infants in Experiment 2 showed strong evidence of having learned and retained information about the global and local forms during familiarization when they received test patterns without a competing source of novelty. Moreover, there was again no indication of a reliable difference in the discriminability of the global and local forms.

Consider now the preference scores for the remaining four conditions, in which the infants received test patterns with two competing sources of novel information. Here the pattern of results is quite different. In only one condition did the infants perform reliably better than chance, and that was when they received a global preference test after familiarization with consistent forms. From this, we may conclude that the introduction of a second source of novelty attracted the infants' attention and disrupted the preference test for novelty. What is more important is that this source of interference was greater when it stemmed from novel global forms than when it stemmed from novel local forms-which we take as evidence for a global precedence effect as defined by Pomerantz (1983) in terms of the relative dominance of the global information.

This conclusion was confirmed by an analysis of variance performed on all of the data from Experiment 2: type of preference test $\times$ consistency of familiarization forms $\times$ familiar test form $\times$ competing source of novelty ( $a b$ sent vs. present) $\times$ order (competing source of novelty first vs. second). There were a number of significant effects, of which the two most important were the interactions between type of preference test and competing source of novelty $[F(1,32)=5.98, p<.05]$ and between these variables and the consistency of the familiarization forms $[F(1,32)=5.23, p<.05]$. Individual comparisons revealed that when there was no competing source of novelty the preference scores were unaffected by the type of preference test or the consistency of the familiarization forms. These preference scores were also reliably higher than the preference scores that were obtained when there was a competing source of novelty, except when there was a global test of preference after familiarization with consistent forms. The latter findings are critical to the issue of whether precedence effects exist. That a competing source of novelty at the global level always interfered with local preference tests, whereas a competing source of novelty at the local level did not always interfere with global preference tests, is consistent with a global precedence effect. ${ }^{4}$ The global information, in other words, was dominant: When global information was novel it always interfered with processing at the local level, but the reverse was not always true. Moreover, the fact that it was when infants had experienced consistent familiarization forms that the global test of preference was not interfered with is interesting and important. It informs us that the two sources of form information, local and global, were not processed independently. Consistent forms resulted in representations of the familiar global form that 
were sufficiently strong to center processing on this familiar global form and the novel global form with which it was paired, without interference from a new source of novelty. We do not know how this occurs, but that this focusing of attention is evident only when the preference test is at the global level speaks to the dominance of this source of information.

With regard to the other significant effects, the preference scores were higher when the familiarization forms had been consistent $[F(1,32)=5.87, p<.025]$ and lower when there was competing novel information $[F(1,32)=16.77, p<.001]$. However, the competing novel information actually produced lower preference scores only when the familiarization forms had been inconsistent $[F(1,32)=6.78, p<.025]$. Finally, there were two interactions that involved the order in which the two types of test trials had been administered. The first involved order and the presence or absence of competing novel forms $[F(1,32)=6.44, p<.025]$; the decrement in preference scores due to a competing source of novelty was greater on the second set of test trials than on the first. Perhaps experiencing the familiarization stimulus again on the first set of test trials enhanced its representation and made the competing novel form that was combined with the familiar test form on the second set of test trials even more attractive and hence more interfering. The second interaction with order involved the type of preference test and the consistency of the familiarization forms $[F(1,32)=9.58, p<.001]$. The major portion of this variance is attributable to two conditions in which there was a local preference test and the test patterns with competing novel forms were administered second. In one case, when the familiarization forms had been consistent, the mean preference score was unexpectedly low; in the other case, when the familiarization forms had been inconsistent, the mean score was unexpectedly high. We have no explanation for this interaction, but inasmuch as it was the result of relatively few individual scores in each condition it may well reflect sampling errors.

In summary, a second source of novelty in the test patterns successfully competed for the infant's attention. Moreover, the magnitude of the interference arising from this form of competition was greater when the preference test involved local, as opposed to global, forms-evidence for a global precedence effect. It is also important and of interest that there was an effect of consistency. That this effect occurred only when there was competition for the infants' attention attests further to the usefulness of an interference paradigm in revealing the processing characteristics of the infant's system for pattern perception.

\section{SUMMARY AND CONCLUSIONS}

The evidence from the present experiments strongly favors the idea that infants 3 and 4 months of age are able to process and remember information about both global and local aspects of geometric arrays. That there was also an effect of consistency supports the contention that these informational sources are not independently processed. These findings are in keeping with views of infant perception that ascribe to even the very young infant the ability to process a wide range of information at more than one structural level, as well as to experience percepts that have considerable organization (see Bomba et al., 1984; Quinn \& Eimas, 1986). The results are not, however, in accord with theoretical positions that describe a course of perceptual development that progresses from the perception of featural (i.e., local) information to the perception of holistic patterns. The latter percepts in some versions of this position are the products of a slow process of association that links the originally independent featural elements into coherent percepts (e.g., Hebb, 1949). The present results are also not in line with theories that assume that perception is initially holistic in nature and that only with development or experience or both are we able to perceive the elements from which the whole is built (e.g., Werner, 1948). In effect, our data argue for the proposition that young infants possess a highly sophisticated processing system for visual form that is not different in terms of its functional properties from that of more mature observers. What is particularly interesting to us is that a precocious perceptual system does not seem to be restricted to the domain of vision, but rather is available for the perception of speech and other auditory events (see Eimas, Miller, \& Jusczyk, 1987).

There was also evidence for a global precedence effect, that is, for the dominance of global information during processing. Such an effect is of theoretical interest only if it cannot be entirely attributed to a difference in discriminability. We believe it cannot be so attributed in the present case, for a number of reasons. First, there were no reliable differences in the preference scores for novel global and local stimuli in both Experiments 1 and 2. Second, if the precedence effect simply reflected a difference in discriminability, it would be difficult to account for the effect of consistency in Experiment 2. Given a large difference in discriminability, favoring the global forms, we would expect the infant's attention to be drawn primarily to the more discriminable forms during familiarization; consequently, the infant's acquisition of knowledge about the global cues or the retention of this knowledge should have been unaffected by the less discriminable local forms. Finally, in a similar vein, the existence of a strong difference in discriminability should have resulted in many more infants' learning about the more discriminable global forms than about the less discriminable local forms. This was not the case: most infants learned about both the global and the local forms. Thus, the precedence effect that was obtained may well be a consequence of the manner in which the infant's processing system evaluates information about visual patterns, although we have as yet no explanation as to how this is actually accomplished. Attempts to uncover the manner in which global precedence and consistency effects arise, as well as the 
generality of these effects, will undoubtedly provide useful insights into the development of our visual processing system.

\section{REFERENCES}

Banks, M. S., \& Salapatek, P. (1983). Infant visual perception. In M. M. Haith \& J. J. Campos (Eds.), Handbook of child psychology: Vol. 2. Infancy and developmental psychobiology (pp. 435-571). New York: Wiley.

BomBA, P. C. (1984). The development of orientation categories between 2 and 4 months of age. Journal of Experimental Child Psychology, 37, 609-636.

Bomba, P. C., Eimas, P. D., Siqueland, E. R., \& Miller, J. L. (1984). Contextual effects in infant visual perception. Perception, 13, 369-376.

Caron, A. J., Caron, R. F., \& Carlson, V. R. (1978). Do infants see objects or retinal images? Shape constancy revisited. Infant Behavior \& Development, 1, 229-243.

Caron, A. J., Caron, R. F., \& Carlson, V. R. (1979). Infant perception of the invariant shape of objects varying in slant. Child Development, 50, 716-721.

Cohen, L. B., \& Gelber, E. R. (1975). Infant visual memory. In L. Cohen \& P. Salapatek (Eds.), Infant perception: From sensation to cognition (Vol. 1, pp. 347-403). New York: Academic Press.

Colombo, J., Laurie, C., Martelli, T., \& Hartig, B. (1984). Stimulus context and infant orientation discrimination. Journal of Experimental Child Psychology, 37, 576-586.

Eimas, P. D., Miller, J. L., \& Jusczy K, P. W. (1987). On infant speech perception and the acquisition of language. In S. Harnad (Ed.), Categorical perception (pp. 161-195). New York: Cambridge University Press.

Enns, J. T., \& Prinzmetal, W. (1984). The role of redundancy in the object-line effect. Perception \& Psychophysics, 35, 22-32.

FAGAN, J. F. (1970), Memory in the infant. Journal of Experimental Child Psychology, 9, 217-226.

HeBb, D. O. (1949). The organization of behavior. New York: Wiley.

HofFman, J. E. (1980). Interaction between global and local levels of a form. Journal of Experimental Psychology: Human Perception \& Performance, 6, 222-234.

KinCHLA, R. A., \& WolfE, J. M. (1979). The order of visual processing: "Top-down," "bottom-up," or "middle-out." Perception \& Psychophysics, 25, 225-231.

Martin, M. (1979). Local and global processing: The role of sparsity. Memory \& Cognition, 7, 476-484.

MCClelland, J. L., \& Miller, J. (1979). Structural factors in figure perception. Perception \& Psychophysics, 26, 221-229.

MILEWSKI, A. E. (1979). Visual discrimination and detection of configurational invariance in 3-month-old infants. Developmental Psychology, 15, 357-363.

MiLler, J. (1981). Global precedence in attention and decision. Journal of Experimental Psychology: Human Perception \& Performance, 6, 1161-1174.

Navon, D. (1977). Forest before trees: The precedence of global features in visual perception. Cognitive Psychology, 9, 353-383.

Navon, D. (1981). The forest revisited: More on global precedence. Psychological Research, 43, 1-32.

Navon, D. (1983). How many trees does it take to make a forest? Perception, 12, 239-254.

Pomerantz, J. R. (1983). Global and local precedence: Selective attention in form and motion perception. Journal of Experimental Psychology: General, 112, 516-540.
Pomerantz, J. R., Sager, L. C., \& Stoever, R. J. (1977). Perception of wholes and of their component parts: Some configural superiority effects. Joumal of Experimental Psychology: Human Perception \& Performance, 3, 422-435.

Quinn, P. C., \& Eimas, P. D. (1986). Pattern-line effects and units of visual processing in infants. Infant Behavior \& Development, 9 , 57-70.

VAN GIFFEN, K., \& HaITH, M. M. (1984). Infant visual response to Gestalt geometric forms. Infant Behavior \& Development, 7, 335-346.

Vurpillot, E., Ruel, J., \& CASTREC, A. (1977). L'organization perceptive chez le nourrisson: Reponse au tout ou a ses elements. Bulle. tin de Psychologie, 327, 396-405.

Weisstein, N., \& Harris, C. S. (1974). Visual detection of line segments: An object superiority effect. Science, 186, 752-755.

WERNER, H. (1948). Comparative psychology of mental development. Chicago: Follett.

Williams, A., \& Weisstein, N. (1978). Line segments are perceived better in coherent contexts than alone: An object-line effect. Memory \& Cognition, 6, 85-90.

\section{NOTES}

1. The findings of Quinn and Eimas (1986, Experiment 2) are also relevant to the study of precedence effects. However, inasmuch as the local elements in that study were quite different from the global properties (line segments vs. configurations) and quite possibly not as discriminable, it was certainly not a strong test of a precedence effect. The results do demonstrate infants' ability to use configural information under some circumstances-the original intention of the study.

2. The logic underlying this reasoning is as follows: Given that the infants were randomly assigned to the local and global tests of novelty preference and that across these conditions they had the same familiarization patterns, the infants must have entered the test trials without knowledge of which preference test would be given and without any differential experience during familiarization. As a consequence, if more infants produced preference scores above $50 \%$ than would be expected by chance for both local and global preference tests, they must have entered the test trials with knowledge of both the local and global forms.

3. All $t$ tests of this nature are one-tailed tests, given the expected preference for the novel stimulus when a discrimination occurs.

4. Given that Kinchla and Wolfe (1979) found that the precedence effect changed from global to local as the size of the forms increased, why we found a global precedence with forms approximately equal to their largest forms is a matter of concern. We suspect that the reason lies in the differences in acuity between infant and adult observers (e.g., Banks \& Salapatek, 1983). Infants at a few months of age are markedly less sensitive to the higher spatial frequencies, the dominant frequencies of small figures. Consequently, infants may require relatively large local figures to give them sufficient information at the lower spatial frequencies to use for recognition of local forms. Even larger local forms would be necessary, or so we assume, before there would be sufficient information to make the local forms perceptually dominant and produce a local precedence effect. If this were true, we should obtain a function that progresses from a global to a local precedence effect as we enlarge the local figures relative to the global forms. In addition, we should find that a smaller local form is needed to produce a local precedence effect as the age of the infant increases.

(Manuscript received February 27, 1987; revision accepted for publication August 5, 1987.) 